\title{
An Internal Equity Evaluation System Based on Merit Measures
}

\author{
Scott Seaman, Carol Krismann, and Fred Hamilton
}

\begin{abstract}
This paper describes a statistical method developed by the Faculty Personnel Committee of the University of Colorado at Boulder Libraries to identify and correct internal salary inequities among its faculty. Initially implemented in the 1995-1996 fiscal year for forty-seven librarians, the process measures an individual's scholarly productivity over his or her entire academic career, accounts for years of experience, and adjusts for his or her most recent annual evaluation rating. The individual's score is then charted against current salary, and a trend line is generated based on the method of least squares. The individual's distance from the trend line indicates possible salary inequity.
\end{abstract}

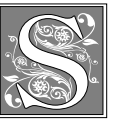

alary equity is a concept used to describe several different compensation disparities found in some salary pay scales. One of the earliest inequities under this rubric was identified as salary compression. Later, it was recognized that differences in pay for the same job also could be attributed to race, class, gender, or age. The Civil Rights Act of 1964, later amended in 1974, and the Equal Pay Act of 1963 included this concern with pay inequity as one of several acts of discrimination against race, age, religion, or sex. ${ }^{1}$ One element of significance in these pieces of legislation was that a legal definition for pay equity was established. At present, salary equity has come to mean "Paying employees according to the skill, effort, responsibilities, and working conditions required by their position regardless of their gender, or race."2 More recently, however, age and religion have been added to this equation.
In the academic environment, salary equity has been an issue for more than two decades. A vast body of literature debates how inequity may be identified, calculated, and attributed. Numerous case studies have been published describing methods to determine salary inequity. But in a paper presented in 1992, Nelle Moore stated:

Conspicuously absent from institutional studies [of salary equity] is any measure of productivity or merit.... The absence of productivity or merit measures in institutional studies after almost twenty years of salary equity research is particularly disturbing. ${ }^{3}$

It is difficult to evaluate the quality of scholarly productivity and, thus, productivity has rarely been included as an equity variable except as a simple count of publications. Instead, the most commonly

Scott Seaman is Associate Director for Administrative Services in the Norlin Library at the University of Colorado; e-mail: seaman@spot.colorado.edu. Carol Krismann is Head of the Business Library at the University of Colorado; e-mail: krismann@colorado.edu. Fred Hamilton is Reference Librarian, English and American Literature, in the Norlin Library at the University of Colorado; e-mail: hamilton@colorado.edu. 
used variables are academic rank, highest degree, or years since terminal degree. Such variables are relatively easy to collect and are not as prone to dispute as subjective productivity measures. ${ }^{4}$ Yet productivity, whether in librarianship, scholarly output, or service activities, represents a critical variable when calculating salary variances. Individuals with the same rank, degree, and years of service may legitimately have different salaries due to productivity differences. Therefore, excluding such measures from equity calculations seriously compromises the validity of any results.

This paper describes a methodology for calculating salary inequity based on productivity measures. The method compares librarians in the same library system with each other (i.e., internally), rather than with librarians in the external market. The intent is to correct salary inequity within the library using peer accomplishments. Other methodologies may then be employed to adjust salaries to the external market.

\section{The Literature}

Besides sheer volume, the pay equity literature can be daunting in its statistical complexity. Perhaps because the issue is so politically charged, academic statisticians continue to argue about esoteric particulars such as effects of multicollinearity or inclusion. Moreover, the statistical technique applied to quantify inequity dramatically impacts the degree of inequity identified. ${ }^{5}$ Not surprisingly, such discrepancies promote vigorous debate concerning the applicability or validity of components or techniques. One exasperated judge lamented that too much of the literature consists of "contests between college professor statisticians who revel in discoursing about advanced statistical theory." 6

Determining equity among individuals in the same profession, but with vastly different educational backgrounds, rank, experience, and expectations, can be fraught with controversy. For example, who should be included in the equity study? Should part-time or administrative staff be excluded? By what variables should individuals be measured? Should individuals be compared based on academic rank, supervisory span, length of service? Much of the literature is concerned with such issues but, after twenty years, offers no universal solutions.

Janice Kirkland argues that an equitable salary structure is cost-effective because it lowers staff turnover. ${ }^{7}$ But, in reality, most equity studies are initiated in response to legal claims of gender or minority bias in salary structure. Consequently, most methodologies outlined in the literature are intended to identify inequities between groups-typically, white males versus a gender or minority subgroup.

Two different methods have evolved to identify salary inequity: paired-comparison and regression analysis. The pairing technique usually involves a one-toone comparison of a member of the minority group with a member of the majority group. Such a process was described by Dorothy D. Nevill at the University of South Florida and Joan McConkey et al at the University of Colorado. ${ }^{8}$ The paired-comparison technique has often been criticized because it can only be used to demonstrate that inequity exists, not to determine its extent. And because the most extreme cases are typically selected as examples, paired-comparison often exaggerates the extent of inequity. ${ }^{9}$

Most recent case studies, however, report using some variation of regression analysis to identify salary inequity, and a considerable number of case studies have been published demonstrating how institutions have applied regression analysis to such studies. ${ }^{10}$ Regression analysis is a statistical method that compares two or more variables, such as salary and sex, to determine their relationship. Within the library literature, several descriptions of such processes exist. ${ }^{11}$

The document most influential in popularizing regression analysis was the American Association of University Pro- 
fessors' Higher Education Salary Evaluation Kit. ${ }^{12}$ This established a model for grouping faculty, identifying valid variables, selecting a regression technique, and interpreting results. Typically, salary is the dependent variable and some measure or combination of measures such as rank, years employed, years since highest degree, and discipline is the independent variable. The differences between each person's actual salary and predicted salary are potential measures of inequity. ${ }^{13}$ Despite questions concerning whether this methodology accurately identifies inequities, it continues to be widely used. ${ }^{14}$

Very few articles focus on establishing equity internally or within an academic department. In the library literature, Gwendolyn Pershing and Mary E. Krutulis describe a process at the University of Indiana Libraries in which equity was analyzed only among library faculty. Using a "Mudge Matrix," the librarians were assigned scores based on degree of external contact, supervision, independence, responsibility, and experience. The total of these scores was used to predict an increment above a predetermined salary base for each librarian. By comparing the predicted salary to the actual salary, a dollar amount of inequity was determined for each eligible faculty member. $^{15}$

In summary, the equity evaluation literature is vast and focuses on the issues of criteria, variables, measurement, and a variety of statistical methods. At the moment, regression analysis seems the method of choice. Merit as a variable is largely ignored. Most of the case studies describe gender and minority equity evaluation systems. The issues are complex, the body of literature is large, and there are many byways in which to wander.

\section{The University of Colorado at Boulder Libraries}

The University of Colorado is a four-campus system with the flagship institution at its Boulder campus. This campus is the research institution and is supported by the university libraries system consisting of a main library and five subject-specialized external branch libraries. The university libraries system on the Boulder campus is a member of the ARL, with total holdings of 2,600,000 books and 18,400 serial subscriptions. In addition, there is an autonomous law library that is not part of this case study.

Boulder campus librarians have faculty status, including significant research, publication, and service responsibilities. At the time of the equity analysis, there were forty-seven faculty members. Of these, twenty were department heads, twenty-four were nondepartment heads, and three were associate directors. Governance within the university libraries is managed by the libraries' faculty. The Faculty Personnel Committee (FPC), one of five elected faculty governance committees, reviews faculty activity in research and service, assesses salary equity, and recommends both compensation awards and equity adjustments to the dean of libraries.

\section{Campus Equity Mandate}

In May 1993, the vice chancellor for academic affairs distributed a memo that contained a draft outline of an equity evaluation system and a charge "for establishing and monitoring procedures which insure equity in faculty salaries."16 Each university department, including the libraries, was to adapt this system to its unit's needs. Before this, no formal systematic equity evaluation had been performed within the libraries.

That memo, and the final version of December 20, 1994, mandated several broad points, including:

- Equity must be based on the individual's entire academic career.

- The process must address equity within the department only.

- Within the department, equity must be calculated on the typical salary and not the extremes.

- The process must be performed, in some form, annually. ${ }^{17}$ 
The dean of libraries requested that the FPC develop a process that would comply with the vice chancellor's memo. Since its conception, this committee has been charged with performing annual performance reviews of each librarian's research and service activities. Combined with the immediate supervisor's review of librarianship, the committee recommends salary increases for each faculty member every year. Because this compensation process was already in place, the FPC was the best-suited faculty committee to develop and implement an equity system.

In addition to the broad points mentioned above, the May 1993 and December 1994 memos placed a major emphasis on the use of quantitative analysis using scatter plots provided to each college by the vice chancellor's Office for Academic Affairs. The scatter plots charted years since terminal degree and present salary, but only for assistant, associate, and full professors. Faculty members with continuing appointments who were at the senior instructor level were not included on the scatter plots. Because senior instructors represented nearly half the libraries' faculty, the charts were of little use. Fortunately, units were given the option of developing alternative approaches for equity comparison. Consequently, theFPC deemed it necessary to devise an internal equity system that would encompass the entire libraries' faculty.

Because this was the first time such a system had been requested by the university, the committee knew that equity evaluation would become part of the $L i$ braries Faculty Handbook. Additions to the handbook necessitate a two-thirds agreement of the libraries' faculty. Thus, throughout the process the committee presented several drafts to the faculty for consultation and approval. A major faculty concern focused on credit for span of supervision and administrative responsibilities. After lengthy discussion, the faculty voted that individuals be compared only with their immediate peers. The FPC resolved this issue by dividing librarians into three groups: department heads, nondepartment heads, and associate directors. Individuals were compared only within the relevant group, thus recognizing differing job responsibilities in a broad way. Consequently, those without personnel or administrative responsibilities would not be unfairly compared with those whose salaries were higher because of additional duties.

\section{Requirements of the Internal Equity System}

The vice chancellor had mandated that equity be determined by merit within each department. Faculty within a department should be equitable relative to one another, but not necessarily with market conditions. Consequently, external measures such as ARL salary estimates or computations of weighted average salaries from comparable institutions were inappropriate data on which to base equity. Instead, equity was to be measured by factors indigenous to the libraries.

Because librarians have such diverse job duties and widely varying experience, assessing merit equity over an individual's entire academic career proved particularly challenging. What constitutes merit, how is it to be measured, and how much and where can supporting information be obtained? The system had to be fair and accurate, but also clear and understandable. A system that was too complex could be burdensome to those reassessing equity every year.

The term developed by the FPC as the measure for equity evaluation over the span of an individual's entire career was career merit. Assessing the career merit of individuals whose primary functions are as diverse as circulation, bibliography, public relations, or computer systems was difficult. However, the libraries' faculty have been awarded annual compensation increases based on merit for some years. Annual merit compensation has been awarded based on three components: the practice of librarianship, scholarly activity, and, service to the profession. 


\begin{tabular}{|c|}
\hline FIGURE 1 \\
Professional Documentation Score \\
\hline \hline 6. Performance above Meritorious in All Three Areas \\
Teaching/librarianship \\
Research/creative work \\
Service \\
5. Performance above Meritorious in Two Areas \\
Teaching/librarianship \\
Research/creative work \\
Service \\
4. Performance above Meritorious in One Area \\
Teaching/librarianship \\
Research/creative Work \\
Service \\
3. Performance is Meritorious at All Levels \\
2. Performance with Qualification \\
1. Performance is Nonmeritorious \\
\hline
\end{tabular}

ous gradations from short book reviews to peer-reviewed articles or books. A similar approach was used for service by considering gradations from membership without attendance at annual conferences to national officeholder. Figure 1 depicts the range of scores an individual could receive for professional documentation.

The annual evaluation score was relatively easy to calculate because it already existed as a numerical measure in other documents. For this component of the career merit score, an average of the faculty member's last three years' annual evaluation scores was calculated. This score was chosen to provide a current perspective to the career merit score. It also provided those with newer careers, who had had no opportunity to produce an extensive professional documentation score, with a comparative element in their career merit measure. Because the professional documentation score tends to favor the more established career, the average annual evaluation score provided a balancing element.

As the literature review suggests, one of the few consistent equity measures used for faculty has been "years since terminal degree." For librarians, this would mean years since earning the MLS. The FPC was initially suspicious of this measure for a number of reasons. First, "years since terminal degree" is not necessarily a measure of quality performance. Some might see it as merely an indicator of longevity. Second, a formula based solely on this criterion would disproportionately reward seniority over the worthy accomplishments of new and midcareer faculty. Third, it was felt that using only this element would not meet the vice chancellor's goals. Finally, the number of years since a librarian achieved the MLS may not be reflective of total professional experience.

Though somewhat suspicious of its relation to merit, the FPC agreed that the measure had some validity. Longevity 


\begin{tabular}{|l|}
\multicolumn{1}{|c|}{ FIGURE 2} \\
Professional Experience Score \\
\hline \hline 6. $25+$ years \\
5. 15 years to 24 years, 11 months \\
4. 7 years to 14 years, 11 months \\
3. 4 years to 6 years, 11 months \\
2. 1 year to 3 years, 11 months \\
1. 0 years to 11 months \\
\hline
\end{tabular}

does demonstrate that performance standards of a position have been consistently achieved over time. Therefore, it was decided to include years of professional experience as a measure, but not as a dominant factor. Also, the FPC decided that "years of professional experience" would be more suitable as a measure than "years since terminal degree." "Professional experience" was defined as the total number of years a librarian had worked in a professional position since receiving the MLS. The FPC calculated the professional experience score by assigning a value of one to six according to ranges of years. Figure 2 shows how these scores were calculated.

Throughout the development of the career merit system, the FPC questioned whether the professional documentation, professional experience, and average annual evaluation scores should be of equal value. After considerable debate, it was decided to weight each measure. This would allow the career merit score to reflect the relative significance of each of its three measures as agreed on by the libraries' faculty.

Therefore, scores for each part were weighted and then combined into a single career merit score. The professional documentation score was weighted at 50 percent. The average annual evaluation score represented 35 percent and the professional experience score only 15 percent of the total.

Weighting was a source of concern for the libraries faculty because varying the percentages for the separate components could dramatically change career merit scores and alter inequity differences among faculty. For example, if the percentage is high for the professional experience segment, those individuals with longevity will be favored. If it is low, new active professionals might be determined as those with the greatest inequity. Nonetheless, after spirited discussion, the libraries faculty voted to accept the weights. Figure 3 outlines an example of how one librarian's career merit score could be computed.

The actual application of the career merit formula began with the FPC gathering the necessary data. For each faculty member, the library administration provided a current vita, internal scholarly review documents, supervisors' reviews of librarianship, and reappointment dossiers, when available. In addition, faculty member were encouraged to submit other documents such as copies of review or reappointment letters or a self-evaluation statement attesting to the quality of their performance in librarianship, research, and service. 


\begin{tabular}{|c|c|c|c|c|c|c|c|c|}
\hline \multicolumn{9}{|c|}{$\begin{array}{c}\text { TABLE } 1 \\
\text { Spreadsheet Calculations } \\
\end{array}$} \\
\hline \multirow[b]{2}{*}{ Name } & \multirow[b]{2}{*}{$\begin{array}{c}1995 \\
\text { Salary }\end{array}$} & \multirow{2}{*}{$\begin{array}{c}\text { Professional } \\
\text { Documentation } \\
\text { Score } \\
\end{array}$} & \multirow{2}{*}{$\begin{array}{c}\text { Professional } \\
\text { Experience } \\
\text { Score } \\
\end{array}$} & \multicolumn{4}{|c|}{ Annual Evaluation } & \multirow{2}{*}{$\begin{array}{r}\text { Career } \\
\text { Merit } \\
\text { Score } \\
\end{array}$} \\
\hline & & & & 1993 & 1994 & & $\begin{array}{c}\text { 3-year } \\
\text { Average }\end{array}$ & \\
\hline Walter & 30,000 & 4.00 & 1.00 & 5.00 & 6.00 & 4.00 & 5.00 & 3.90 \\
\hline Melvin & 26,500 & 3.00 & 3.00 & 2.30 & 2.90 & 2.50 & 2.60 & 2.86 \\
\hline Diana & 35,000 & 4.00 & 3.00 & 5.70 & 5.00 & 5.80 & 5.50 & 4.38 \\
\hline Patsy & 28,000 & 5.00 & 2.00 & 4.00 & 3.75 & 5.00 & 4.25 & 4.29 \\
\hline Barry & 31,000 & 3.00 & 4.00 & 3.10 & 3.30 & 2.90 & 3.10 & 3.19 \\
\hline
\end{tabular}

Each FPC member was designated "principal reader" for a certain number of files. He or she carefully reviewed the faculty member's file and assigned a numeric score to each of the three categories. Following the principal reader's review, the FPC met to act as a secondary reviewing body. The principal reader presented an evaluation of the faculty member and justification for the scores assigned. This evaluation was then discussed by the FPC and accepted or modified by consensus.

\section{Equity Data Analysis}

After the three scores were assigned, faculty members' names, salaries, and various scores were entered into a spreadsheet (see table 1). The spreadsheet was designed to automatically calculate a single, weighted, career merit score for each faculty member.

The next step was to present the data statistically in a way that would reveal salary inequities. In keeping with the faculty's decision to compare individuals only with their immediate peers, three scatter plots were created: one for department heads, one for nondepartment heads, and one for associate directors. To ensure accuracy, the charting function of the spreadsheet software was used to createeach plot, with salaries charted on the vertical axis and career merit scores charted on the horizontal axis.
Theoretically, comparing career merit scores against salaries would reveal any equity discrepancies. Faculty with similar scores should receive similar salaries. For example, in figure 4, Diana has the highest career merit score and is the highest-paid faculty member, whereas Melvin has the lowest merit score and is paid the lowest salary. Within this example of five faculty members, Melvin and Diana are properly compensated because the individual who has the highest merit score is paid the highest salary. However, the figure also shows that Patsy's merit score is very similar to Diana's, yet Patsy is paid a much lower salary. Thus, Patsy may be a candidate for an equity adjustment.

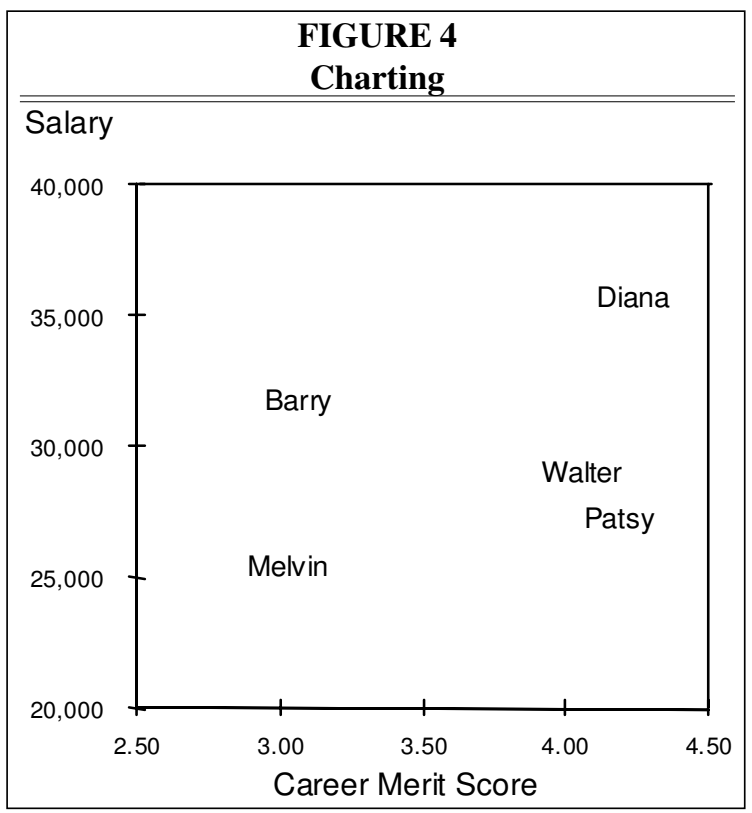


But assigning a specific dollar amount to Patsy's inequity is difficult given only the information presented on this chart. Moreover, the vice chancellor mandated that equity be calculated based on the department's typical salary and not the extreme. Diana's salary, being the highest, represents the extreme. Consequently, Patsy's equity is not simply the $\$ 7,000$ difference between the two salaries. Applying equity in such a manner would result in creating equity only between Patsy and Diana; it would not create salary equity throughout the department.

However, a departmental salary trend line can be calculated based on the five charted points.

FIGURE 5

Trend Line

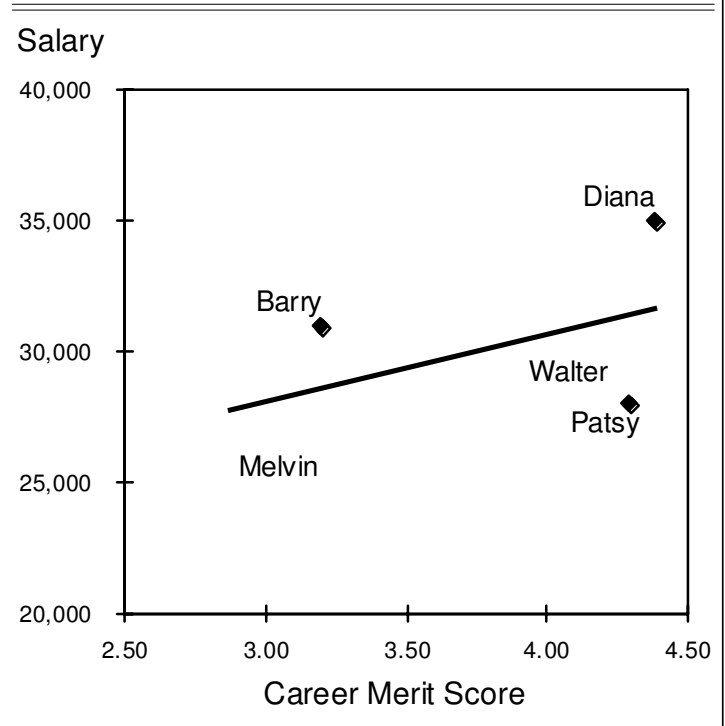

Most spreadsheet packages can automatically calculate trend lines based on charted data. Figure 5 shows the trend line for the department based on the scores and salaries of all five faculty members. This trend line predicts the ideal salary for any career merit score. Thus, a faculty member in this department with a career merit score of 3.5 would earn slightly more than $\$ 30,000$. For example, Walter is salaried very close to his ideal, Patsy is salaried well below the ideal, and Melvin, the poorest performer, is salaried only slightly below his predicted equity.

Not only does distance from the trend line provide a visual expression of inequity from the salary norm, but it can easily be calculated. For example, Patsy's distance from the trend line is about $\$ 3,000$. Increasing her salary by that amount will bring her salary into equity based on the salaries of the entire group and not just the salary of an individual.

\section{Limitations}

For purpose of demonstration, the previous example was simplified to a single department of only five librarians. In reality, this method was successfully imple- mented in the 1995-1996 fiscal year for forty-seven librarians. After applying the system for three years, the result has been greater salary equity among librarians at CU Boulder.

However, this method has limitations. These include the perceived accuracy and consequential interpretation of the results, the applicability to small groups, and the subjectivity of a key part of the process.

Perhaps the most significant limitation is that results must be interpreted in the proper context. Charts of numbers with trend lines lend themselves to literal interpretations. The tendency is to conclude that everyone who falls below the trend line is underpaid and everyone above is overpaid. But this is not the case. Distances from the trend line may not always be the result of inequity. Unusual workloads, for example, may justify salary differences between individuals within peer groups. Moreover, the numbers comprising the career merit score were not so precise as to preclude some variation in scores of similar individuals. Therefore, considerable knowledge and judgment must be used in interpreting the results.

It became evident early in the process 


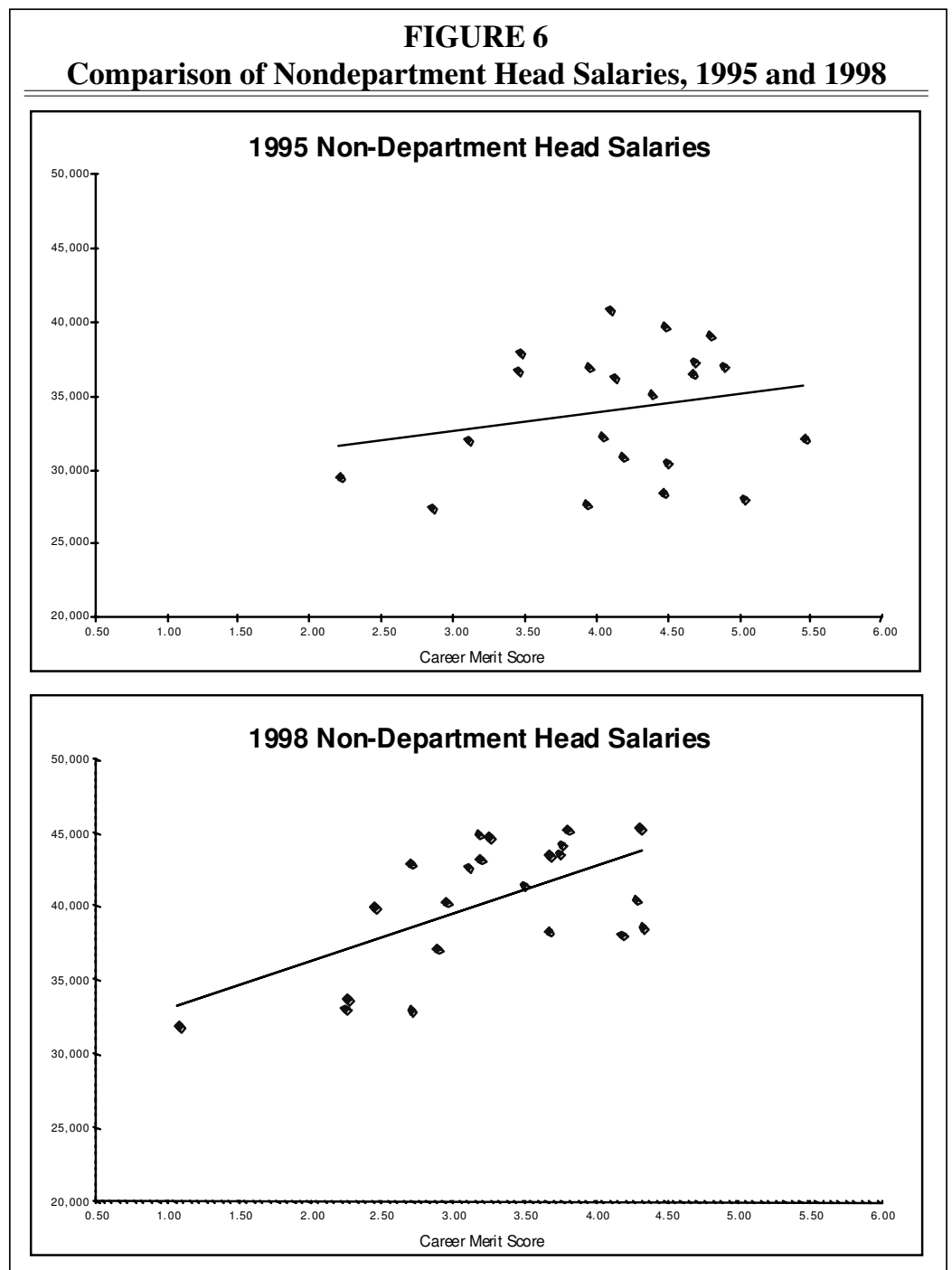

that the three associate directors could not be included in the equity analysis because their duties were more extensive and their salaries were higher. But creating a separate peer group only for the associate directors resulted in irrational results. A meaningful trend could not be discerned from only three points of data. Also, the dean of libraries could not be included because there was no other person on which to compare equity. The dean represented a peer group of one, and this methodology requires peer groups of approximately five or more. The committee concluded that data from very small peer groups were unreliable and, reluctantly, decided to exclude the associate directors and dean from the process.

Finally, 50 percent of a librarian's career merit score, the professional documentation component, is subjective. This is not inherently a weakness because subjectivity adds flexibility in the interpretation and scoring of an individual's career. If the career merit scores were not somewhat subjective, the methodology would be too inflexible to accommodate the myriad circumstances surrounding librarians' careers. However, this subjectivity can become a weakness if there is no con- 
sistency among various generations of FPC members in terms of how the professional documentation score is assigned.

\section{Conclusions}

The university's mandate to the libraries was to implement an equity appraisal based on merit that spanned the individual's entire academic career. Additional mandates were that the process could not take into account market factors or extreme salaries. The libraries resolved this dilemma by developing a quantifiable system that ranked each faculty member by using a combination of recent annual evaluations, research and service as expressed on the vita, and years in the profession. The weighted score then was charted against current salary and a trend line was generated. An individual's distance from the trend line indicated possible salary inequity.

Despite its limitations this method has proved workable. Figure 6 is a comparison of the libraries' nondepartment head trend lines in 1995, prior to application of the method, and in 1998, following three years of use. These charts are not directly comparable because the career merit score scale was reduced from a possible six to five in 1997. However, they imply greater salary equity among the nondepartment head librarians. The slope of the 1998 line is steeper, indicating that those with higher career merit scores are being paid higher relative to the rest of the group. Moreover, the wide variations in salaries for the same career merit scores have been reduced.

This use of this system is the first time the University of Colorado libraries system has honored accomplishments throughout a person's entire academic career. Inevitably, the analysis has limitations. Even so, the system has successfully identified faculty with career merit inequities and has, over several years' application, helped produce in a more equitable compensation structure within the university libraries.

\section{Notes}

1. The Equal Pay Act of 1963 was an amendment to the Fair Labor Standards Act of 1938, a major law that set federal levels for fair labor practices. One of the major purposes of the Equal Pay Act was to include in the Fair Labor Standards Act the stipulation that "No employer shall discriminate ... between employees on the basis of sex by paying wages ... at a rate less than the rate at which he pays wages to employees of the opposite sex . . . for equal work on jobs the performance of which requires equal skill, effort, and responsibility . . ." However, executive, administrative, and professional employees were exempted from its standards for pay equity. To somewhat rectify this situation, the Education Amendment of 1972, in those areas related to the Fair Labor Standards Act, indicates that the Equal Pay Act of 1963 also would apply to professionals in institutions of higher education receiving federal financial assistance.

2. Janice J. Kirkland, "The High Cost of Low Salaries: Strong Reasons for Pay Equity," Bottom Line 5/6 (spring 1991): 11-13.

3. Nelle Moore, "Faculty Salary Equity: Issues in Regression Model Selection," Research in Higher Education 34 (Feb. 1993): 124.

4. Barbara B. Reagan and Betty J. Maynard, "Sex Discrimination in Universities: An Approach through Internal Labor Market Analysis," AAUP Bulletin 60 (spring 1974): 13-21; Daniel S. Hamermesh et al, "Scholarship, Citations and Salaries: Economic Rewards in Economics," Southern Economic Journal 49 (Oct. 1982): 472-81; J. Scott Long et al, "Sex Differences and Productivity in Academic Rank Advancement," American Sociological Review 58 (Oct. 1993): 703-22.

5. Carol Joyce Blumberg, "A Study of Salary Equity at a Teaching-Oriented Undergraduate Institution Using Multiple Models" (paper delivered at the American Educational Research Association Annual Meeting, San Francisco, Apr. 20, 1992), ERIC ED 351 359; Robert K. Toutkoushian, "Issues in Choosing a Strategy for Achieving Salary Equity" (paper delivered at the Thirty-Fourth Annual Forum of the Association for Institutional Research, New Orleans, May 29, 1994), ERIC, ED 373 649; Denise A. Krallman, "Faculty Salary Equity: Comparison of Two Methodologies" (paper delivered at the Thirty-Fourth Annual Forum of the Association for Institutional Research, New Orleans, May 29, 1994), ERIC, ED 373 673; Garrett C. Schau and Vivian H. Heyward, "Salary Equity: Similarities and Differences in Outcomes from Two Different Common Prediction Models," American Education Research Journal 24 (summer 1987): 271-86. 
6. Otero v. Mesa County Valley School District, 470 F. Suppl. 326, 331 (D. Colo. 1979).

7. Kirkland, "The High Cost of Low Salaries," 11.

8. Dorothy D. Nevill, "Achieving Salary Equity," Educational Record 56 (fall 1975): 266-70; Joan McConkey et al, "Salary Equity: A Case Study," College \& Research Libraries 54 (Jan. 1993): 33-41.

9. Thomas R. Pezzullo and Barbara E. Brittingham, "The Assessment of Salary Equity: A Methodology, Alternatives, and a Dilemma," in Salary Equity: Directing Sex Bias in Salaries among College and University Professors (Lexington, Mass.: Lexington Bks., 1979), 4.

10. Marshall E. Drummond, "Dealing with Faculty Salary Inequity-A Case Study" (paper delivered at the Thirty-Fourth Annual Forum of the Association for Institutional Research, New Orleans, May 29, 1994), ERIC, ED 373 617; Blumberg, "A Study of Salary Equity at a TeachingOriented Undergraduate Institution Using Multiple Models."

11. Maureen Pastine and Shirley McLean, "Pay Equity in Libraries," Bottom Line 7 (summer 1993): 7-12; Carolyn Kenady, "Identifying Sex-based Wage Discrimination," in Pay Equity: An Action Manual for Library Workers (Chicago: ALA, 1989), 15-22.

12. Elizabeth L. Scott, Higher Education Salary Evaluation Kit (Washington, D.C.: American Association of University Professors, 1977).

13. Mary P. Martin and John D. Williams, "Effects of Statewide Salary Equity Provisions on Institutional Salary Policies: A Regression Analysis," in Salary Equity: Detecting Sex Bias in Salaries among College and University Professors (Lexington, Mass.: Lexington Bks., 1979), 57-67.

14. Gerald W. McLaughlin et al, "Multicollinearity and Testing Questions of Sex Equity," Research in Higher Education 19 (1983): 277-84.

15. Gwendolyn Pershing and Mary E. Krutulis, "Using a Value Engineering Technique to Determine Salary Equity among Academic Librarians," Library Administration \& Management 10 (fall 1996): 240-45.

16. Memo of May 5, 1993, to deans, department chairs, and institute directors from Bruce R. Ekstrand, vice chancellor for academic affairs.

17. Memo of December 20, 1994, to deans, department chairs, institute directors, the BFA Executive Committee, and the Salary Process Committee from Bruce R. Ekstrand, vice chancellor for academic affairs. 